\title{
The Retailers' Choices of Profit Strategies in a Cournot Duopoly: Relative Profit and Pure Profit
}

\author{
Feifei Zheng \\ School of Management, Jinan University, Guangzhou, China \\ Email: 2897054522@qq.com
}

How to cite this paper: Zheng, F.F. (2017) The Retailers' Choices of Profit Strategies in a Cournot Duopoly: Relative Profit and Pure Profit. Modern Economy, 8, 199-210. https://doi.org/10.4236/me.2017.82014

Received: December 13, 2016 Accepted: February 17, 2017

Published: February 20, 2017

Copyright $\odot 2017$ by author and Scientific Research Publishing Inc. This work is licensed under the Creative Commons Attribution International License (CC BY 4.0).

http://creativecommons.org/licenses/by/4.0/ (c) (i) Open Access

\begin{abstract}
To investigate the influence of the relative performance on retailers' choices of profit strategies, a Cournot competition model composed of two private retailers is proposed, in which retailers are facing the problem of choosing a strategy from pure profit and relative profit. The study shows that, 1) when its competitor pursues relative profit, the retailer will adopt pure profit strategy if the degree of relative performance of its competitor is high enough. Otherwise, the retailer will adopt the relative profit strategy. 2) The more relative profit-maximizing retailers there are, the more intense market competition will be, the lower market price will decrease. 3) Under a certain degree of relative performance, the strategy profiles (relative profit, relative profit), (relative profit, pure profit) and (pure profit, relative profit) are all likely to be Nash equilibrium, except the strategy profile (pure profit, pure profit).
\end{abstract}

\section{Keywords}

Relative Profit, Pure Profit, Cournot Competition, Nash Equilibrium

\section{Introduction}

A good profit target is very important to the survival and development of the enterprise. For a long time, most of economists always assume that enterprises pursue the maximization of absolute profit, without consideration of whether the profit target is the best choice for the enterprise. Especially with the increase of market competition, it has been difficult for the absolute profit target to satisfy the owners' desire for benefits. Rather, more and more enterprises started to pursue relative profit maximization, that is, they care not only about their absolute profit, but also consider their profit relative to that of their competitors [1] [2]. Besides, managers who pay more attention to relative profits will put more 
weight on the difference between their own profits and their rival's profits, as a result, their market behavior will be more aggressive.

Actually, seeking relative performance is based on human nature. A wealthy man will be unhappy when he realizes that his neighbors are all millionaires. On the contrast, a beggar may also feel fortunate after seeing another's miserable life. And it is the same to enterprises like automobile manufacturers, dairy product factories, and computer manufactures et al. They all keep an eye on competitors' performance when they try to improve their own profits.

There have been a lot of researches about relative profit in recent years. For example, Vega-Redondo [3] pointed out that firms' owners always evaluate their managers' performances based on relative profits rather than pure profits in the context of evolutionary stability. Lu [4] and Nakamura [5] investigated the competition between one social welfare-maximizing public firm and one generalized relative profit-maximizing private firm. However, more researches conducted concentrated on competition between private firms. In the context of private oligopoly, Jansen [6] found that a firm using relative performance evaluation would earn more profits when its competitor chases for pure profit. But if two competitors chase for relative profits simultaneously, they may catch in the quagmire of vicious competition as a result [7]. Besides, Matsumura et al. [8] investigate the relationship between the severity of competition among firms and their ability to collude, by introducing relative performance in their objective functions. And his research showed that the more intense market competition is, the less likely firms are to collude with each other. Matsumura [9] further investigated the relationship between the degree of competitiveness in a market and R\&D expenditure.

In a word, although the predecessors have made some important research results, but there are still some problems worth exploring further: 1) most current studies assume that each enterprise have a specific profit target exogenously, and then discuss the problem of market competition, while ignoring the problem of endogenous selection of profit targets, that is, which profit target enterprise would like to pursue in the face of relative profit and absolute profit, and whether relative profit target is always better than absolute profit in any situation? It is the main problem the paper is going to solve. 2) Existing researches always assume enterprises pay same attention to relative profits, which apparently simplifies the realistic situation too much. If enterprises have different degree of importance of relative performance, then would this difference influence their choices of profit strategy? Besides, it is our intuition that the more we concentrate on relative profit, the more likely we take the profit strategy and aggressive market behaviors. Is this intuition true? It is also a problem discussed in this paper.

To solve the problems mentioned above, we build up a mixed duopoly Cournot model composed of two retailers who sell homogeneous products and face the problem of choosing an appropriate profit target between relative profit and absolute profit at the same time. In order to investigate how the degree of im- 
portance of relative performance influences retailers' choices of profit strategy, we assume the two retailers have different degree of importance of relative performance, as indicated by Kolstad [10].

The remainder of this paper is organized as follows. In Section 2, we formulate a mixed duopolistic model composed of two retailers. Section 3 is the main body of this paper, in which we derive the subgame perfect Nash equilibrium in the model and find the equilibrium market structures. Section 4 summarizes the full text, highlights some innovative conclusion in this paper, and points out future research direction in the end.

\section{The Model}

We consider a Cournot duopoly for a single homogeneous product with normalized linear inverse demand given by $P=1-q_{1}-q_{2}$, where $P$ is the market price of product, and $q_{i}$ represent retailer $i$ 's sale quantity, $i=1,2$. Using $Q=q_{1}+q_{2}$ represents the total market sales, then we have $P=1-Q$.

We suppose that the marginal sell costs of retailers 1 and 2 are constant and identical. Let $w$ denote retailer $i$ 's marginal cost $(i=1,2)$. In addition, we assume that $w<1$ in order to ensure both retailers make profits.

Consequently, the profit function of retailer $i$ is

$$
\pi_{i}=\left(a-q_{i}-q_{j}-w\right) q_{i}, i, j=1,2
$$

If the retailer $i$ pursues relative profit pursuit, then the objective function can be written as:

$$
\pi_{i}-\alpha_{i} \pi_{j}, i, j=1,2
$$

Therefore, when retailer has different profit strategies, their objective functions can be written respectively as

$$
\begin{aligned}
& \prod_{i}=\left\{\begin{array}{l}
\pi_{i}-\alpha_{i} \pi_{j}(r \text { strategy }) \\
\pi_{i}(p \text { strategy })
\end{array}\right. \\
& i, j=1,2
\end{aligned}
$$

where $p$ represents pure profit and $r$ represents relative profit and $\alpha_{i}$ represents the degree of importance of relative performance of retailer $i$. And the bigger $\alpha_{i}$ is, the more aggressively retailer $i$ would behave, and the more intense market competition will be.

Since the degree of importance of relative performance is our research focus, the assumptions are given in order to facilitate the following analysis.

Assumption 1: We assume the two retailers have different degree of importance of relative performance, which means $\alpha_{i} \neq \alpha_{j}$. And $\left(\alpha_{i}, \alpha_{j}\right)$ is common knowledge for both retailers.

Assumption 2: We assume $\alpha_{i}$ is exogenous as it's our belief that $\alpha_{i}$ is always constant as long as its manager's beliefs don't change.

The game runs as follows. In the first stage, retailers 1 and 2 simultaneously choose whether to adopt pure profit strategy or relative profit strategy. In the second stage, after observing the choice of the strategies by the rival in the first 
stage, retailers determine their quantity in the market simultaneously and independently, on the basis of their decisions in the first stage.

\section{Equilibrium Analysis of the Strategic Variable Selection Game}

In this section, we investigate the four possible subgames which are classified on the basis of each firm's strategic variable selected in the first stage: 1) retailers 1 and 2 pursues pure profit maximization ( $p-p$ game); 2 ) retailer 1 pursues relative profit while retailer 2 pursues pure profit $(r-p$ game); 3$)$ retailer 1 pursues pure profit while retailer 2 pursues relative profit ( $p-r$ game); 4 ) retailers 1 and 2 pursues relative profit maximization ( $r-r$ game). We use superscripts $p p, r p, p r, r r$ respectively to represent different subgames in the following paper.

\section{1. $p-p$ Game}

If both retailers chase for pure profit maximization, the reaction functions of retailers 1 and 2 are given as follows:

$$
\begin{aligned}
& q_{1}=\frac{1}{2}\left(1-w-q_{2}\right) \\
& q_{2}=\frac{1}{2}\left(1-w-q_{1}\right)
\end{aligned}
$$

yielding

$$
\begin{aligned}
q_{1}^{p p} & =\frac{1}{3}(1-w), q_{2}^{p p}=\frac{1}{3}(1-w) \\
Q^{p p} & =\frac{2}{3}(1-w), P^{p p}=\frac{1}{3}(1+2 w) \\
\pi_{1}^{p p} & =\frac{1}{9}(1-w)^{2}, \pi_{2}^{p p}=\frac{1}{9}(1-w)^{2}
\end{aligned}
$$

\section{2. $r-p$ Game}

If retailer 1 pursues relative profit while retailer 2 pursues pure profit, the reaction functions of retailers 1 and 2 are given as follows:

$$
\begin{gathered}
q_{1}=\frac{1}{2}\left[1-w-\left(1-\alpha_{1}\right) q_{2}\right] \\
q_{2}=\frac{1}{2}\left(1-w-q_{1}\right)
\end{gathered}
$$

yielding

$$
\begin{gathered}
q_{1}^{r p}=\frac{(1-w)\left(1+\alpha_{1}\right)}{3+\alpha_{1}}, q_{2}^{r p}=\frac{(1-w)}{3+\alpha_{1}} \\
Q^{r p}=\frac{(1-w)\left(2+\alpha_{1}\right)}{3+\alpha_{1}}, P^{r p}=\frac{1+\left(2+\alpha_{1}\right) w}{3+\alpha_{1}} \\
\pi_{1}^{r p}=\frac{(1-w)^{2}\left(1+\alpha_{1}\right)}{\left(3+\alpha_{1}\right)^{2}}, \pi_{2}^{r p}=\frac{(1-w)^{2}}{\left(3+\alpha_{1}\right)^{2}}
\end{gathered}
$$


With a further comparison of $p-p$ and $r-p$ game, we can find how retailer's profit changes if he transform his strategy from pure profit to relative profit while his rival stays the same. And the results are summarized as Proposition 1.

Proposition 1. Comparing $p-p$ and $r-p$ game, we can find that

1) $q_{1}^{r p}>q_{1}^{p p}, q_{2}^{r p}<q_{2}^{p p}$, and $\frac{\partial\left(q_{1}^{r p}-q_{1}^{p p}\right)}{\partial \alpha_{1}}>0, \frac{\partial\left(q_{2}^{r p}-q_{2}^{p p}\right)}{\partial \alpha_{1}}<0$.

2) $\pi_{1}^{r p}>\pi_{1}^{p p}, \pi_{2}^{r p}<\pi_{2}^{p p}$, and $\frac{\partial\left(\pi_{1}^{r p}-\pi_{1}^{p p}\right)}{\partial \alpha_{1}}>0, \frac{\partial\left(\pi_{2}^{r p}-\pi_{2}^{p p}\right)}{\partial \alpha_{1}}<0$.

3) $Q^{r p}>Q^{p p}, P^{r p}<P^{p p}$, and $\frac{\partial\left(P^{r p}-P^{p p}\right)}{\partial \alpha_{1}}<0$.

Proposition 1 shows that, if retailer 2 still holds on pure profit maximization while retailer 1 changes his mind, retailer 1 would like to increase his order quantity and make more profit. On the contrast, retailer 2 has to decrease order quantity to minimize his losses. Besides, it is found that the more retailer 1 pays attention to relative profit, the more goods he will order, and the more profit he will make. Similarly, order quantity and profit of retailer 2 are all negatively related to the degree of relative performance of retailer 1 . In addition, the total sales in the market increase and the price of goods decrease due to a more fierce competition, which is resulted from retailer 1's aggressive market behavior.

\section{3. $p$ - r Game}

If retailer 1 pursues pure profit while retailer 2 pursues relative profit, the reaction functions of retailers 1 and 2 are given as follows:

$$
\begin{gathered}
q_{1}=\frac{1}{2}\left(1-w-q_{2}\right) \\
q_{2}=\frac{1}{2}\left[1-w-\left(1-\alpha_{2}\right) q_{1}\right]
\end{gathered}
$$

yielding

$$
\begin{gathered}
q_{1}^{p r}=\frac{(1-w)}{3+\alpha_{2}}, q_{2}^{p r}=\frac{(1-w)\left(1+\alpha_{2}\right)}{3+\alpha_{2}} \\
Q^{p r}=\frac{(1-w)\left(2+\alpha_{2}\right)}{3+\alpha_{2}}, P^{p r}=\frac{1+\left(2+\alpha_{2}\right) w}{3+\alpha_{2}} \\
\pi_{1}^{p r}=\frac{(1-w)^{2}}{\left(3+\alpha_{2}\right)^{2}}, \pi_{2}^{p r}=\frac{(1-w)^{2}\left(1+\alpha_{2}\right)}{\left(3+\alpha_{2}\right)^{2}}
\end{gathered}
$$

Since $p-r$ game is symmetrical with $r-p$ game, so is the result. In this case, retailer 2 who chases for relative profit will make more profit, and the increment of profit is positively related to the degree of relative performance of his own.

\section{4. $r$ - r Game}

If both retailers pursue relative profit, the reaction functions of retailers 1 and 2 
are given as follows:

$$
\begin{aligned}
& q_{1}=\frac{1}{2}\left[1-w-\left(1-\alpha_{1}\right) q_{2}\right] \\
& q_{2}=\frac{1}{2}\left[1-w-\left(1-\alpha_{2}\right) q_{1}\right]
\end{aligned}
$$

yielding

$$
\begin{gathered}
q_{1}^{r r}=\frac{(1-w)\left(1+\alpha_{1}\right)}{3+\alpha_{1}\left(1-\alpha_{2}\right)+\alpha_{2}}, q_{2}^{r r}=\frac{(1-w)\left(1+\alpha_{2}\right)}{3+\alpha_{1}\left(1-\alpha_{2}\right)+\alpha_{2}} \\
Q^{r r}=\frac{(1-w)\left(2+\alpha_{1}+\alpha_{2}\right)}{3+\alpha_{1}\left(1-\alpha_{2}\right)+\alpha_{2}}, P^{r r}=\frac{1+\left(2+\alpha_{1}+\alpha_{2}\right) w-\alpha_{1} \alpha_{2}}{3+\alpha_{1}\left(1-\alpha_{2}\right)+\alpha_{2}} \\
\pi_{1}^{r r}=\frac{(1-w)^{2}\left(1+\alpha_{1}\right)\left(1-\alpha_{1} \alpha_{2}\right)}{\left(3+\alpha_{1}\left(1-\alpha_{2}\right)+\alpha_{2}\right)^{2}}, \pi_{2}^{r r}=\frac{(1-w)^{2}\left(1+\alpha_{2}\right)\left(1-\alpha_{1} \alpha_{2}\right)}{\left(3+\alpha_{1}\left(1-\alpha_{2}\right)+\alpha_{2}\right)^{2}}
\end{gathered}
$$

Comparing the order quantities, price and profits of two retailers in $r-p$ and $r-r$ game, we can find the following results, which can be summarized as Proposition 2.

Proposition 2. Comparing $r-p$ and $r-r$ game, we can find that

1) $q_{1}^{r r}<q_{1}^{r p}, \frac{\partial\left(q_{1}^{r r}-q_{1}^{r p}\right)}{\partial \alpha_{1}}>0, \frac{\partial\left(q_{1}^{r r}-q_{1}^{r p}\right)}{\partial \alpha_{2}}<0 ; q_{2}^{r r}>q_{2}^{r p}, \frac{\partial\left(q_{2}^{r r}-q_{2}^{r p}\right)}{\partial \alpha_{1}}>0$, $\frac{\partial\left(q_{2}^{r r}-q_{2}^{r p}\right)}{\partial \alpha_{2}}>0$.

2) $Q^{r r}>Q^{r p}, \quad P^{r r}<P^{r p}, \frac{\partial\left(P^{r r}-P^{r p}\right)}{\partial \alpha_{1}}<0, \frac{\partial\left(P^{r r}-P^{r p}\right)}{\partial \alpha_{2}}<0$.

3) $\pi_{1}^{r r}<\pi_{1}^{r p}, \frac{\partial\left(\pi_{1}^{r r}-\pi_{1}^{r p}\right)}{\partial \alpha_{1}}<0, \frac{\partial\left(\pi_{1}^{r r}-\pi_{1}^{r p}\right)}{\partial \alpha_{2}}<0$.

4) $\pi_{2}^{r r} \leq \pi_{2}^{r p}$ if $\frac{-1-3 \alpha_{2}+2 \sqrt{1+2 \alpha_{2}+2 \alpha_{2}^{2}}}{1+\alpha_{2}} \leq \alpha_{1}<1$, and $\pi_{2}^{r r}>\pi_{2}^{r p}$ if $0 \leq \alpha_{1}<\frac{-1-3 \alpha_{2}+2 \sqrt{1+2 \alpha_{2}+2 \alpha_{2}^{2}}}{1+\alpha_{2}}$.

Proof: It is easy to prove the results of (1), (2) and (3), thus the following only provides the proof of result of (4)

Since

$$
\begin{aligned}
\pi_{2}^{r r}-\pi_{2}^{r p} & =\frac{(1-w)^{2}\left(1+\alpha_{2}\right)\left(1-\alpha_{1} \alpha_{2}\right)}{\left(3+\alpha_{1}\left(1-\alpha_{2}\right)+\alpha_{2}\right)^{2}}-\frac{(-1+w)^{2}}{\left(3+\alpha_{1}\right)^{2}} \\
& =(1-w)^{2}\left[\frac{\left(1+\alpha_{2}\right)\left(1-\alpha_{1} \alpha_{2}\right)}{\left(3+\alpha_{1}\left(1-\alpha_{2}\right)+\alpha_{2}\right)^{2}}-\frac{1}{\left(3+\alpha_{1}\right)^{2}}\right]
\end{aligned}
$$

Letting $\frac{\left(1+\alpha_{2}\right)\left(1-\alpha_{1} \alpha_{2}\right)}{\left(3+\alpha_{1}\left(1-\alpha_{2}\right)+\alpha_{2}\right)^{2}}-\frac{1}{\left(3+\alpha_{1}\right)^{2}}=0$, we have

$$
\alpha_{1}=\frac{-1-3 \alpha_{2}+2 \sqrt{1+2 \alpha_{2}+2 \alpha_{2}^{2}}}{1+\alpha_{2}} .
$$


While $\alpha_{1}=-1$ and $\frac{-1-3 \alpha_{2}-2 \sqrt{1+2 \alpha_{2}+2 \alpha_{2}^{2}}}{1+\alpha_{2}}$ are removed.

Thus, we have $\pi_{2}^{r r}-\pi_{2}^{r p} \leq 0$ if $\frac{-1-3 \alpha_{2}+2 \sqrt{1+2 \alpha_{2}+2 \alpha_{2}^{2}}}{1+\alpha_{2}} \leq \alpha_{1}<1$ and $\pi_{2}^{r r}-\pi_{2}^{r p}>0$ if $0<\alpha_{1}<\frac{-1-3 \alpha_{2}+2 \sqrt{1+2 \alpha_{2}+2 \alpha_{2}^{2}}}{1+\alpha_{2}}$.

Proposition 2 indicates that, if retailer 1 holds on relative profit maximization while retailer 2 changes his strategy from pure profit to relative profit, retailer 2's profit will not necessarily increase. It depends on degree of importance of relative performance of both retailers.

Precisely speaking, in this case, the relative profit-maximizing retailer 1 will reduce his orders while his rival increases the order quantity. This is because retailer 2's pursuing relative profit leads to a more fiercely competitive market and, as a result, weakens retailer 1's competitive advantages. Moreover, the decrement of retailer 1's order quantity is negatively related to his own degree of importance of relative performance while positively related to that of his rival. On the contrast, retailer 2's increment of orders is positively related to both firms' degree of relative performance.

In addition, the price of goods falls further if both retailers seek for relative profit maximization. It is easy to explain this phenomenon, when retailers in the market are all carrying on aggressive behavior, market competition will be more intense. Consequently, retailers are likely to get lost in price competition, which undoubtedly reduces retailer 1's profit as his order quantity falls down too.

As for retailer 2, if he pursues pure profit, market competition will be soft and he may benefit from higher price of goods. If he pursues relative profit, he may benefit from more sales. Thus, retailer 2 should trade off between these two strategies while retailer 1 chases for relative profit. When $\alpha_{1}$ is big enough relative to $\alpha_{2}$, that is $\frac{-1-3 \alpha_{2}+2 \sqrt{1+2 \alpha_{2}+2 \alpha_{2}^{2}}}{1+\alpha_{2}} \leq \alpha_{1}<1$, the losses caused by low price dominate positive influence of more sales, as a result, retailer 2 should pursue pure profit. Otherwise, he should take the relative profit strategy.

\subsection{Equilibrium Analysis}

By choosing the profit strategy of retailers 1 and 2 endogenously in the first stage, we derive the equilibrium strategy profiles in the subgame perfect Nash equilibrium. In this subsection, we investigate whether the strategy profiles for the $p-p, r-q, p-r$ and $r-r$ games can be the Nash equilibrium; this depends on both retailers' degree of importance of relative performance $\alpha_{1}$ and $\alpha_{2}$. The first stage of the game is summarized in Table 1. Given the above consequences for the four subgames in the second stage, we now discuss each retailer's choice of a profit strategy in the first stage.

According to Table 1 and Propositions 1 and 2, we have Proposition 3 from easy calculations, when $\left(\alpha_{1}, \alpha_{2}\right) \in(0,1)$. 
Table 1. The first stage game.

\begin{tabular}{ccc}
\hline Retailer 1 & Pure profit & Relative profit \\
\hline Pure profit & $\left(\pi_{1}^{p p}, \pi_{2}^{p p}\right)$ & $\left(\pi_{1}^{p r}, \pi_{2}^{p r}\right)$ \\
Relative profit & $\left(\pi_{1}^{r p}, \pi_{2}^{r p}\right)$ & $\left(\pi_{1}^{r r}, \pi_{2}^{r r}\right)$ \\
\hline
\end{tabular}

\section{Proposition 3.}

1) In area $\mathrm{I}\left\{\left(\alpha_{1}, \alpha_{2}\right) \mid 0 \leq \alpha_{1}<\min \left\{\alpha_{1}^{*}, \alpha_{1}^{* *}\right\}, 0 \leq \alpha_{2}<1\right\}, \quad \pi_{1}^{r p}>\pi_{1}^{p p}, \quad \pi_{2}^{p r}>$ $\pi_{2}^{p p}, \pi_{1}^{r r}>\pi_{1}^{p r}$ and $\pi_{2}^{r r}>\pi_{2}^{r p}$ are satisfied, implying that $r-r$ game is observed to be the unique equilibrium strategy profile.

2) In area $\mathrm{II}\left\{\left(\alpha_{1}, \alpha_{2}\right) \mid \alpha_{1}^{* *} \leq \alpha_{1}<\alpha_{1}^{*}, 0 \leq \alpha_{2}<2 \sqrt{3}-3\right\}, \pi_{1}^{r p}>\pi_{1}^{p p}, \pi_{2}^{p r}>\pi_{2}^{p p}$, $\pi_{1}^{r r}>\pi_{1}^{p r}$ and $\pi_{2}^{r r} \leq \pi_{2}^{r p}$ are satisfied, implying that $r-p$ game is observed to be the unique equilibrium strategy profile.

3) In area $\operatorname{III}\left\{\left(\alpha_{1}, \alpha_{2}\right) \mid \alpha_{1}^{*} \leq \alpha_{1}<\alpha_{1}^{* *}, 2 \sqrt{3}-3 \leq \alpha_{2}<1\right\}, \quad \pi_{1}^{r p}>\pi_{1}^{p p}, \quad \pi_{2}^{p r}>$ $\pi_{2}^{p p}, \pi_{1}^{r r} \leq \pi_{1}^{p r}$ and $\pi_{2}^{r r}>\pi_{2}^{r p}$ are satisfied, implying that $p-r$ game is observed to be the unique equilibrium strategy profile.

4) In area $\operatorname{IV}\left\{\left(\alpha_{1}, \alpha_{2}\right) \mid \max \left\{\alpha_{1}^{*}, \alpha_{1}^{* *}\right\}<\alpha_{1}<1, \sqrt{5}-2 \leq \alpha_{2}<1\right\} ， \pi_{1}^{r p}>\pi_{1}^{p p}$, $\pi_{2}^{p r}>\pi_{2}^{p p}, \pi_{1}^{r r}<\pi_{1}^{p r}$ and $\pi_{2}^{r r}<\pi_{2}^{r p}$ are satisfied, implying that both $p-r$ game and $r-p$ game are observed to be equilibrium strategy profiles.

Proof:

$$
\begin{gathered}
\pi_{1}^{r p}-\pi_{1}^{p p}=\frac{(1-w)^{2}\left(3-\alpha_{1}\right) \alpha_{1}}{9\left(3+\alpha_{1}\right)^{2}}>0 ; \\
\pi_{2}^{p r}-\pi_{2}^{p p}=\frac{(1-w)^{2}\left(3-\alpha_{2}\right) \alpha_{2}}{9\left(3+\alpha_{2}\right)^{2}}>0 ; \\
\pi_{1}^{r r}-\pi_{1}^{p r}=(1-w)^{2}\left[-\frac{1}{\left(3+\alpha_{2}\right)^{2}}+\frac{\left(1+\alpha_{1}\right)\left(1-\alpha_{1} \alpha_{2}\right)}{\left(3+\alpha_{1}\left(1-\alpha_{2}\right)+\alpha_{2}\right)^{2}}\right],
\end{gathered}
$$

Apparently, we have $\pi_{1}^{r r}-\pi_{1}^{p r}>0$ if $\alpha_{1}<\alpha_{1}^{*}=\frac{3-2 \alpha_{2}-\alpha_{2}^{2}}{1+6 \alpha_{2}+\alpha_{2}^{2}}$ and $\pi_{1}^{r r}-\pi_{1}^{p r} \leq 0$ if $\alpha_{1} \geq \alpha_{1}^{*}$.

$$
\pi_{2}^{r r}-\pi_{2}^{r p}=(1-w)^{2}\left[-\frac{1}{\left(3+\alpha_{1}\right)^{2}}+\frac{\left(1+\alpha_{2}\right)\left(1-\alpha_{1} \alpha_{2}\right)}{\left(3+\alpha_{1}\left(1-\alpha_{2}\right)+\alpha_{2}\right)^{2}}\right]
$$

Similarly, we have $\pi_{2}^{r r}-\pi_{2}^{r p}>0$ if $\alpha_{1}<\alpha_{1}^{* *}=\frac{-1-3 \alpha_{2}+2 \sqrt{1+2 \alpha_{2}+2 \alpha_{2}^{2}}}{1+\alpha_{2}}$ and $\pi_{2}^{r r}-\pi_{2}^{r p} \leq 0$ if $\alpha_{1} \geq \alpha_{1}^{* *}$, where $\alpha_{1}^{*}=\frac{3-2 \alpha_{2}-\alpha_{2}^{2}}{1+6 \alpha_{2}+\alpha_{2}^{2}}$ is the inverse function of $\alpha_{2}=\frac{-1-3 \alpha_{1}+2 \sqrt{1+2 \alpha_{1}+2 \alpha_{1}^{2}}}{1+\alpha_{1}}$.

Besides, it can be calculated that when $\alpha_{1}^{*}=\alpha_{1}^{* *}$, we have $\alpha_{1}=\alpha_{2}=2 \sqrt{3}-3$ and when $\alpha_{1}^{*}=1$, we have $\alpha_{2}=\sqrt{5}-2$.

Figure 1 shows the results of Proposition 3. We state the ranking orders of the 
payoffs of retailers 1 and 2 for the four areas shown. In Figure $1, \alpha_{1}^{*}$ and $\alpha_{1}^{* *}$, which are the threshold values of $\alpha_{1}$ as the function of retailer 2's degree of importance of relative performance $\alpha_{2}$, divide $\left(\alpha_{1}, \alpha_{2}\right)$ into four parts and each part corresponds to different equilibrium strategy profile(s). Precisely speaking, when both $\alpha_{1}$ and $\alpha_{2}$ are low enough, shown as area I, both retailers will take relative profit strategy. Besides, when $\alpha_{1}$ is big enough than $\alpha_{2}$, shown as area II, retailer 1 will take relative profit strategy while his rival chases for pure profit. On the contrary, retailer 2 will pursue relative profit if he concentrates more on relative profit shown as area III. Finally, when both $\alpha_{1}$ and $\alpha_{2}$ are sufficiently high, as shown as area IV, either $p-r$ game or $r-p$ game is observed to be equilibrium strategy profile, that is , every one of them is likely to choose relative profit strategy but they never can chase for relative profit as the same time, there must be one giving in market competition.

Proposition 3 shows that, when both retailers' degree of importance of relative performance $\alpha_{1}$ and $\alpha_{2}$ are low enough, shown as area I in Figure 1, $r-r$ game is observed to be the unique equilibrium strategy profile, which points out that relative profit is the dominant strategy for both retailers in area I. Once taking the strategy, neither of them is likely to change strategy alone. This result indicates both retailers' pursuing relative profit maximization is more likely to happen in a moderate competitive market.

Besides, when retailer 1's degree of importance of relative performance is high but not sufficiently high relative to that of retailer 2, shown as area II in Figure $1, r-p$ game is observed to be the unique equilibrium strategy profile. This is because as retailer 1's pays more attention to relative profit, market competition will be more intense if both retailers continue to pursue relative profit, which forces the dominated one to change his strategy to earn more profits from a relatively mild competition. Similarly, it is the same for retailer 1 to change strategy if rival's degree of importance of relative performance is high but not sufficiently high relative to his, which is shown as area III in Figure 1.

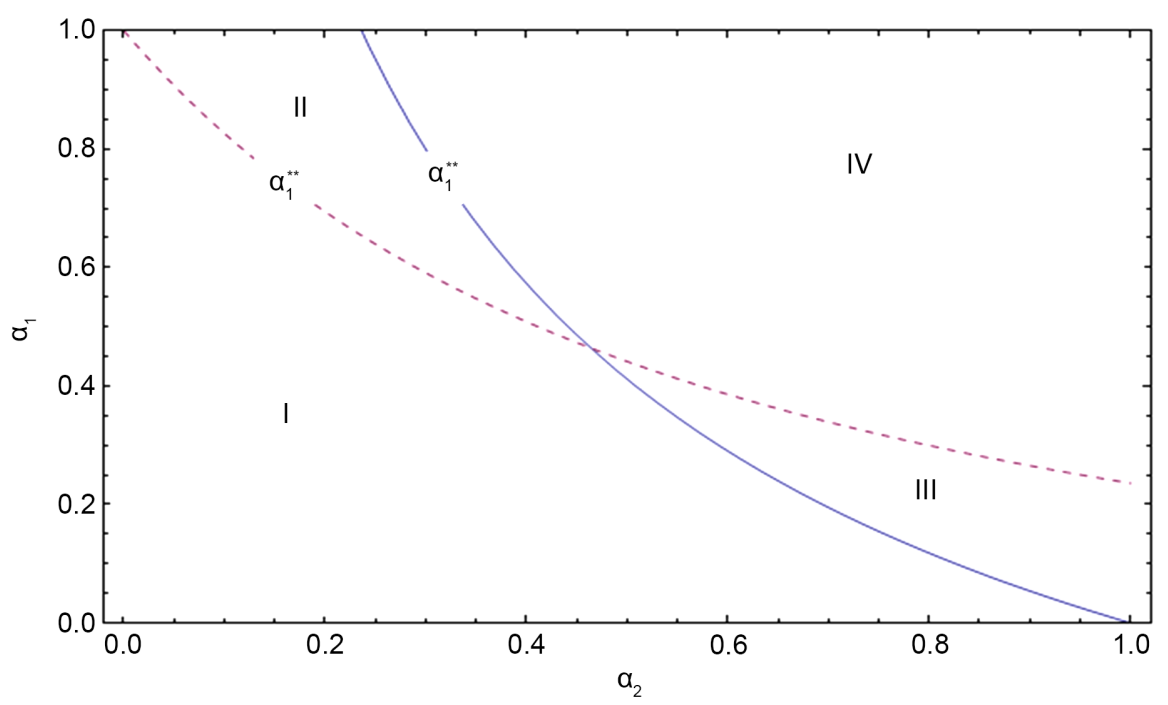

Figure 1. Areas I to IV for the optimal profit strategy of retailers 1 and 2. 
Finally, when both $\alpha_{1}$ and $\alpha_{2}$ are sufficiently high, as shown as area IV in Figure 1, either $p-r$ game or $r-p$ game is observed to be equilibrium strategy profile. This is because when both retailers put much weight on the difference between own profits and their rival's profits, their market behavior will be more aggressive, which leads to a more intense market competition. To ease the competition, there must be one retailer giving up his relative profit strategy. (By the way, $p-p$ game can't be the equilibrium result, as once a retailer takes pure profit strategy, the other would undoubtedly pursue relative profit.) However, since no retailer dominates in the market, every one of them is willing to chase for relative profit. Consequently, there are two equilibrium strategy profiles in this area.

\section{Conclusions}

While most current studies concentrated on the problem of market competition of enterprises given a specific profit target exogenously, this paper investigated each retailer's endogenous choice of a profit strategy in a mixed duopoly with homogeneous goods composed of two private retailers. More precisely, we investigated the situation in which both retailers endogenously choose either a relative profit strategy or a pure profit strategy in the market competition in the fashion of Jansen [6]. Our research proved Jansen's conclusion that firm can make more profits by pursuing relative profit when the rival chase for pure profit maximization. But there are some different conclusion compared with his research, and it is our theoretical contribution to this issue.

In contrast to the results for a standard mixed duopoly composed of two enterprises in Jansen [6], who pointed out the dominant strategy is to design a contract with a managerial bonus based on relative profits evaluation, we showed that the strategy profiles (relative profit, relative profit), (relative profit, pure profit) and (pure profit, relative profit) are all likely to be Nash equilibrium under a certain degree of relative performance, that is, enterprises should take pure profit strategy rather than relative profit under a certain situation.. And it is true in our daily life. When facing a rival who behaves aggressively in market competition, it may be not bad for an enterprise to make some concessions by pursuing pure profit maximization. Taking retailers for example, if one retailer chases for relative profit and put too many goods into market, it would lead to a fierce competition if the others act in the same way as a response. Rather, chasing for pure profit and putting less goods may relieve the competition and let the enterprise make more money.

Besides, we found that when market competition is fiercely intense, enterprise which has a higher degree of relative performance may chase for pure profit maximization. That is, the more enterprise concentrates on relative profit, the less likely he would take the relative profit strategy in a fiercely competitive market. It also can be found in actual market competition. If there is fierce competition between enterprises, they are likely to change their profit targets to relieve the competition, especially when they concentrate too much on relative 
profit.

The results of this paper have certain limitations, which points out several relevant topics in further research. Firstly, we assume the degree of relative performance is common knowledge for both retailers, but in reality the retailers may not see his rival's emphasis on relative performance, so the game between retailers is more likely to be incomplete information game. Precisely speaking, if the enterprise has no idea how the rival emphasis on relative performance, or he only knows the probability distribution of rival's degree of relative performance, what the final equilibrium would be? Secondly, we only concern about the competition between retailers, which is the end of a supply chain. However, there is no doubt that retailers' choices will make a big influence on manufacture's profit, thus the manufacture may participate in the retailers' game by controlling the wholesale price, so that the situation of tripartite game may take place, which means there should be a three-stage game. In the first stage, manufacture decides his wholesale price, then retailers choose their profit strategy and in the third stage, they compete on quantity. Finally, only homogeneous goods are taken into consideration in our study, so what the equilibrium strategy profile will be if we add substitutability into our basic model. How does the substitutability of goods influence retailers' choices? It is also worth further research.

\section{References}

[1] Miller, N.H. and Pazgal, A.I. (2001) The Equivalence of Price and Quantity Competition with Delegation. RAND Journal of Economics, 32, 284-301. https://doi.org/10.2307/2696410

[2] Miller, N. and Pazgal, A. (2002) Relative Performance as a Strategic Commitment Mechanism. Managerial and Decision Economics, 23, 51-68. https://doi.org/10.1002/mde.1045

[3] Vega-Redondo, F. (1997) The Evolution of Walrasian Behavior. Econometrica, 65, 375-384. https://doi.org/10.2307/2171898

[4] Lu, Y. (2011) The Relative-Profit-Maximization Objective of Private Firms and Endogenous Timing in a Mixed Oligopoly. The Singapore Economic Review, 56, 203 213. https://doi.org/10.1142/S0217590811004201

[5] Nakamura, Y. (2015) Price versus Quantity in a Mixed Duopoly: The Case of Relative Profit Maximization. Economic Modelling, 44, 37-43. https://doi.org/10.1016/j.econmod.2014.09.019

[6] Jansen, T., van Lier, A. and van Witteloostuijn, A. (2009) On the Impact of Managerial Bonus Systems on Firm Profit and Market Competition: The Cases of Pure Profit, Sales, Market Share and Relative Profits Compared. Managerial and Decision Economics, 30, 141-153. https://doi.org/10.1002/mde.1437

[7] Kou, Z. and Zhou, M. (2015) Hotelling's Competition with Relative Performance Evaluation. Economics Letters, 130, 69-71. https://doi.org/10.1016/j.econlet.2015.02.011

[8] Matsumura, T. and Matsushima, N. (2012) Competitiveness and Stability of Collusive Behavior. Bulletin of Economic Research, 64, s22-s31. https://doi.org/10.1111/j.1467-8586.2012.00439.x

[9] Matsumura, T., Matsushima, N. and Cato, S. (2013) Competitiveness and R\&D 
Competition Revisited. Economic modelling, 31, 541-547. https://doi.org/10.1016/j.econmod.2012.12.016

[10] Kolstad, J.T. (2013) Information and Quality When Motivation Is Intrinsic: Evidence from Surgeon Report Cards. The American Economic Review, 103, 2875 2910. https://doi.org/10.1257/aer.103.7.2875

Submit or recommend next manuscript to SCIRP and we will provide best service for you:

Accepting pre-submission inquiries through Email, Facebook, LinkedIn, Twitter, etc. A wide selection of journals (inclusive of 9 subjects, more than 200 journals)

Providing 24-hour high-quality service

User-friendly online submission system

Fair and swift peer-review system

Efficient typesetting and proofreading procedure

Display of the result of downloads and visits, as well as the number of cited articles Maximum dissemination of your research work

Submit your manuscript at: http://papersubmission.scirp.org/

Or contact me@scirp.org 